Check for updates

Montreal, Canada

Cite this as: $B M J$ 2021;372:n590 http://dx.doi.org/10.1136/bmj.n590 Published: 01 March 2021

\title{
Researcher broke embargo to leak BMJ paper to Trump administration
}

\section{Owen Dyer}

A medical researcher who took a political appointment with the Trump administration while working on a major international meta-analysis of potential covid-19 treatments leaked a preprint version of the research to senior government colleagues last year, documents released in a congressional investigation show. ${ }^{1}$

Paul Alexander, a former assistant professor at McMaster University in Canada who specialises in health research methods, wrote in an email to Stephen Hahn, commissioner of the Food and Drug Administration (FDA), that the research lent support to a role for hydroxychloroquine.

The FDA authorised the antimalarial on an emergency basis last April under pressure from Trump, but revoked this in June, citing the drug's "known risks" and stating that it was "no longer reasonable to believe" that it was effective against covid-19.

Alexander's email came a month later, on 19 July, addressed to Hahn, deputy FDA commissioner Anand Shah, and health department press chief Michael Caputo, who had recently appointed Alexander as his scientific advisor.

"Hi Dr Hahn and Anand and Michael," he wrote. "I share this submission (embargoed) so highly confidentially, please share with no one not even in people who work or report to you."

He went on, "I thought of it long and hard as the group submitted last night to BMJ after revisions. I weighed the balance and this is so important and such an emergency and while I have not done this before and will not again, I share this embargoed so that you are primed of what we found if it could help your decision making to help the USA and the globe as the US leads the globe, rightly."

Alexander appeared to reference his Trump support, writing, "You would know the one reason why I stand out among this group of some [of] the world's top researchers which I am proud of and made the personal decision to reveal it."

Reed Siemieniuk of McMaster University, who led the meta-analysis published in The $B M J,{ }^{2}$ said that Alexander had contributed "very early on to the first iteration" as part of a team screening titles and abstracts. "Paul stepped off of the research group prior to contributing to additional updates, when at the same time he notified us that he had taken a position working for the US government."

A note at the end of the article reads, "We thank Paul Alexander (who was an author in the previous version of this review) for input and early contributions." Siemieniuk told The BMJ, "I was not aware of the breach of embargo until now.”
Neither the final published analysis, which appeared in The BMJ on 30 July, nor the document leaked by Alexander 11 days earlier recommended hydroxychloroquine as a covid-19 treatment or suggested any survival benefit, instead singling out the drug for its high rate of adverse events.

In his email, Alexander directed the FDA's attention to a paragraph which appeared to suggest a reduction in mean symptom duration in patients taking hydroxychloroquine, but the finding is described as "low certainty" and the paragraph ends by saying "there was no other benefit and there was apparent risk of adverse events."

There was no change in the FDA's position following Alexander's intervention and in October the US National Institutes of Health recommended against using hydroxychloroquine in hospitalised covid-19 patients.

Alexander lost his job with the health department in September, after leaked emails showed him peremptorily instructing the Centers for Disease Control and Prevention director, Robert Redfield, to make editorial changes to the agency's flagship publication, Morbidity and Mortality Weekly Report. ${ }^{3}$ He did not respond to a request for comment.

Document released by representative James Clyburn (D-SC). House Select Subcommittee on the coronavirus crisis. February 2021. https://coronavirus.house.gov/sites/democrats.coron-

avirus.house.gov/files/07.19.2020\%20SSCC-0005448_Redacted.pdf

Siemieniuk RAC, Bartoszko J), Ge L, et al. Drug treatments for covid-19: living systematic review and network meta-analysis. BM/2020;370:m2980.

Dyer O. Trump appointees tamper with renowned CDC publication, claiming that scientists are trying to "hurt the president.". BMJ2020;370:m3589. 